dades no cubiertas por el AUGE), con una las personas que se enferman, y nieguen $\quad$ 2. Creación de un mercado público de prima comunitaria ajustada por edad y cobertura a condiciones preexistentes a compra y venta de seguros privados garantizado (56 enfermedades), con una cion sean factibles, la ley introduce:

$\begin{array}{ccc}\text { garantizado } 56 \text { enfermedades), con una } & \text { ciones sean factibles, la ley introduce: } & \text { mercado regulado por el gobierno y ad- } \\ \text { prima comunitaria plana asociada a un } & \text { Un mandato obligatorio. En un siste- } & \text { ministrado por los estados o por institu- }\end{array}$ prina compensación. La prima comunitaria

y edad, correspondiente al plan complementario, comprende el $96,8 \%$ del total de las cotizaciones y está regulada de acuerdo a una banda de precios. De acuerdo a
la ley, el factor de la mujer cotizante no la ley, el factor de la mujer cotizante no podrá ser mayor a 9 veces (entre el mibre cotizante a 14. Esta regulación limita a dos las tablas por Isapre (antes usaban miles) pero les da libertad para escoger su nivel de precios.

La prima comunitaria plana está acompañada de una compensación ex post a las Isapre a través de un Fondo de Compen-
sación de Riesgos. Así, personas considesación de Riesgos. Así, personas consideradas de más riesgo para las Isapre paga-
rán una prima menor a su costo esperado, pero la Isapre recibirá una prima cercana a su precio esperado. Este Fondo lo administra la Superintendencia de Salud, que calcula y supervisa las transferencias de compensaciones netas entre los seguros. Actualmente no supera el 3.2\% del total la práctica es un programa piloto.

Sin embargo, el espiritu de la ley en la práctica no se ha cumplido: en el reglamento que elaboró la Superintendencia
en consultas con las Isapre, la ley solo se en consultas con las Isapre, la ley solo se que se han trasladado a un nuevo plan con posterioridad a la entrada en vigencia de la ley. En la práctica esto excluye a los adultos mayores y a las personas con enfermedades crónicas, que, como vimos, no pueden cambiarse a nuevos planes. En la práctica, la ley sólo se aplica al $46 \%$ de los afiliados.

LA REFORMA EN ESTADOS UNIDOS Y LO QUE PUEDE SERVIR PARA CHILE

1. Nuevas reglas para todos los seguros prohíbe, a partir de 2014, que los seguros privados individuales voluntarios grupales, y los nuevos mercados de seguros públicos que se crearán, ponga límites de por vida o anuales al gasto en
la cobertura, cancelen el plan de salud a a de seguro privado, no se puede exigir ceptar a todos los interesados, con sus que se pueda demandert también que los nos compren un seguro. De este modo, a propuesta incluye un mandato obligacompra de seguros. Si los rabajadores optan por no comprar cobertura, se enfrentan a una multa.

Beneficios de salud y tipo de planes. forma establece un paquete esencial de eneficios de salud. Se crearon cinco tipo de planes de beneficios, que van desde al $90 \%$ de cobertura. Tambien hay nelan catastrófico, pero solo para los planes inividuales voluntarios. Estos requerimientos establecidos por el goerno, incluyendo un paquete de presciones mínimas, con servicios prevenivos y curativos, topes a los copagos $y$ deducibles y a los precios de las primas. Regulacion de las primas. La ley estalos precios pueden variar de acuerdo a la edad con un factor de 1:3, lo que significa que una persona mayor no deberia pagar más de tres veces el valor de lo que paga una pessora joven. Adrás se estipula que las prinas no podrian

Ajuste de riesgo. Las primas comuniarias tienen varios problemas. Si se implementan sin ajuste de riesgo o un mecanismo compensador hacia los seguros, hay fuertes riesgos de selección adversa, y emigración de los buenos riesgos lo que podría conducir a una espiral de
costos. Por eso la legislación también costos. Por eso la legislación también contempla el establecimiento de fondo de similar al Fondo de Compensacion de lo similar al Fondo

Informar la proporción de la prim utilizada en servicios clínicos y ofrecer descuentos a los consumidores si dichos pon inferiores al 85\%, para los tempres seguros individuales voluntarios y pequeñas empresas. ciones sin fines de lucro, los consumidores podrian comprar un seguro, comparar los teneficios y los precios, y elegir el plaa aue nor se adapte a sus necesida mercacoara, además, un segundo tipo de mercahas empresas (hasta de 100 empleados). Esta modalidad es radicalmente diferente a mantener el contrato de seguros mbito privado e individual, porque n ente público toma en sus manos tecion de agregar y promediar los riesgos, y trata de beneficiarse de las econothas de escala y el poder negociador que a posición le brindaria a los usuarios. io provendrán de los seguros privados, pero también de cooperativas de consumidores sin fines de lucro. Esto significa que los seguros privados con o sin fines tir bajo las mismas reglas.

3. Subsidios para la compra de primas El gobierno proporcionaría subsidios para comprar primas dentro de los intercambios a personas y familias con ingresos que fluctuen entre el $133 \%$ y el $400 \%$ (U) 8.2. L anuales para una familia de cuaMrán a una escasa que limita se vincupor parte de los usuarios entre el $2 \%$ del reso anual -para los que se encuenran en el 133\% de la línea de pobrezahasta 9,5\% para los que se ubiquen entre el 300 y el 400\% de dicho límite. Otra dimensión de la reforma es la propuesta que introduce cuentas de ahorro ligadas al monto de los copagos y dedueibles. Estas cuentas no son flexibles, y se vinculan a planes de salud con altos de estos ahorros es que son liberados de impuestos. Si los intermediarios públicos, las empresas y las personas desean seguros asequibles con primas bajas, ello necesariamente será acompañado de altos deducibles y copagos, pero esta financiarlos.

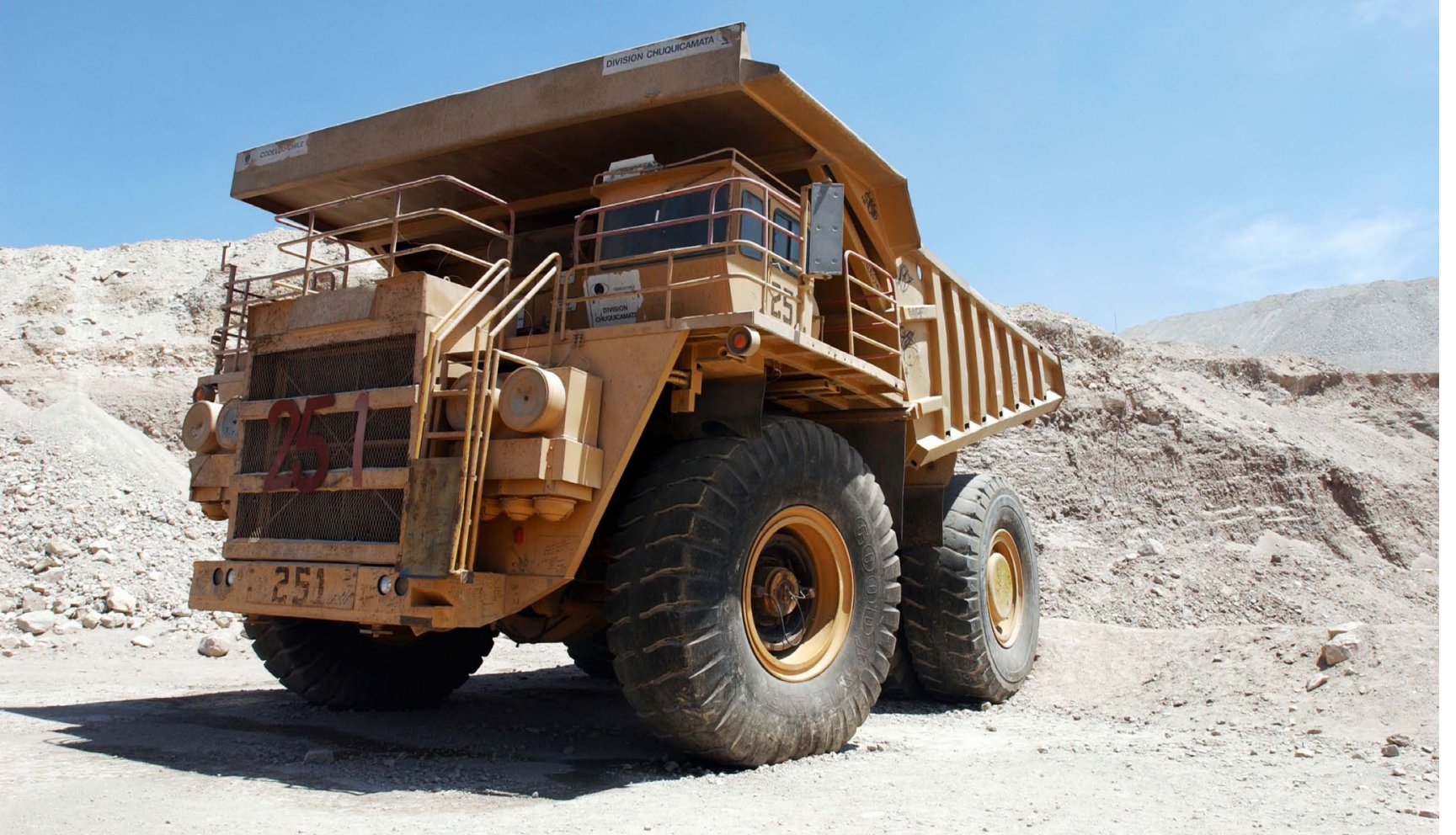

\section{De vuelta al royalty}

El royalty a la minería del cobre fue parte bajo la administración Lagos, con el fin de del paquete para financiar la reconstrucción. financiar un Fondo de Innovación para la Pero si lo aumentamos, ipor qué entonces Competitividad, lo que está de acuerdo con $\begin{array}{ll}\text { no cobrar también impuestos especificos a } & \text { acumular riqueza renovable (en este caso, } \\ \text { otros sectores de grandes empresas? } & \text { conocimiento). Año a año la Ley de Presu- }\end{array}$ otros sectores de grandes empresas? Un político pragmático diría "pero si da puestos establece sus usos específicos. mismo qué impuesto, stupid!!" Pero no da lo Pero otro proyecto de ley, uno que busca mismo. Usar el royalty para financiar gastos normar aspectos institucionales relativos de reconstrucción, varios de ellos de tipo co- la administración y definición anual de los yuntural y de corto plazo, nos plantea revi- programas que dicho Fondo financiaría, llesar la razon de un royaly min pla de organizarnos como sociedad para lograr decir: hoy lo recaudado por el royalty queda se objetivo.

La lógica básica para cobrar un royalty Le las rentas vos (riqueza renovable) que reemplacen, en hecho con los fondos del royalty.

el largo plazo, a la fuente inicial de rentas. Para que el royalty cumpla su objetivo La motivación es simple: si no se invierte lógico se requiere aislar de mejor forma los parte de la renta mineral en crear riqueza fondos por acumularse, de la discreción del renovable, se enfrenta el riesgo de tener gobierno de turno. Ello requiere una institupan para hoy y hambre para mañana. En el cionalidad con responsabilidad legal clara y ideal del ABC financiero, lo anterior presu- sujeta a auditorías transparentes sobre los alcanzar un nivel permanente de capital y proyecto en hibernación, que norma estos con una estructura de riesgo y plazos de aspectos, otorga demasiado poder y discre maduración acordes, de forma que en règimen sus retornos financien un dividendo perpetuo a la población beneficiada. Pero nada de esto ha sido mencionado en el re-

El royalty minero fue instaurado en 2005 ción al ejecutivo.

Dadas las tentaciones del mundo político, no parece facil lograr una normativa adecuada. Pero estamos en la vispera del Bicenenario. Así, frente a grandes desafios sólo queda tener grandes sueños.
* Ph.D. en Economia, Univer-
sity of London (QMC). Profe-
sor Facultad de Economia y

Oe

Decano: Jorge Rodríguez Grossi

economiayneogcios.uahurtadado. Producción OE: Comunicar. Escuela de $O E$ es una revista de circulación gratuit. 